\title{
Experience of Patients with Vertigo: a Case Study
}

\author{
Faqih Ruhyanudin*, Lutfi Agung Priambodho \\ Departement of Nursing, Faculty of Health Science, Universiy of Muhammadiyah Malang, \\ Jl. Bendungan Sutami 188 A Malang, Jawa Timur \\ *Corresponding author : faqih@umm.ac.id
}

\begin{abstract}
Background: Erratic vertigo disorders, drugs that continue to be consumed, and environmental conditions cause stress so it can cause depression. Vertigo is an important problem to be studied in order to obtain the data in a complete qualitative related to the complaint and its impacted both to physical and psychological and social.Objectives: to explore the experiences experienced, felt, and thought by vertigo sufferers in dealing with their health status before, during and after vertigo attacks. To identify what did the changes occur to the bio-psycho-socio-spiritual Vertigo sufferers in living their daily lives with their vulnerable conditions of recurrence. Method: This research used qualitative design with case study approach. Data collected in depth-interview form to 7 participants who had Experiencing of vertigo more than a year in Janti Health Center Malang. Participants selected by Purposive Sampling technique. Data analysis used Colaizzi method. Results: identified six themes of this study: (1) Vertigo Arrived Suddenly, (2) Physical and Psychological Stressor Caused Recurrence, (3) Physical Discomforts to the Impact of Vertigo, (4) Vertigo sufferers at risked of physical injury, (5) Strived to Reduce Vertigo, (6) Required support from family's and nearby person. Conclusion: Vertigo causes made the patient's condition becomes very unstable and greatly affect the daily living.
\end{abstract}

Keywords: Vertigo's Experience, Case Study

\section{INTRODUCTION}

Vertigo is a symptom that is often difficult to define precisely. In general, the term vertigo (from the Latin relate) is indicated by the symptomatic characteristics of the clinical form of discomfort in the body. Vertigo can be one of four dizziness components, consisting of (1) vertigo, (2) presyncope, (3) disequilibrium, and (4) Lightheadedness. In general, complaints of vertigo attack with duration not long, just a few minutes to several hours later complaints disappear. However, sometimes vertigo recur after a few months or several years ((Lumbantobing, 2004; Gnerre et al, 2015)

Vertigo arises from asymmetry in racti vestibular from damage or dysfunction of the labyrinth, vestibular nerve, or central vestibular structures in the brain stem. Impaired body equilibrium tool resulting in a mismatch between the actual body position and what is perceived by the central nervous system. Vertigo May be functional and unrelated to changes or damage to the anatomy of organs in the brain. However, the occurrence of tension or increased pressure on the membranes of the brain or large blood vessels in the brain or in the intra-cranial can cause severe pain that is often referred to as Vertigo. Conventional causes of vertigo are distinguished by (1) central vertigo, central nervous disorders, and (2) peripheral vertigo, peripheral nerve disorders occur. Vertigo complaints may arise suddenly or gradually. Vertigo is also common because of peripheral equilibrium disorders that may occur due to anatomical changes or due to a simple 
physiological reaction that can interfere with and arise suddenly during head position changes, called benign paroxysmal positional vertigo (BPPV), or acute peripheral vestibulopathy (APV). If at the time of the vertigo attack arises and is in an unsafe place then it can lead to injury. (Wreksoatmodjo, 2004; Dewanto, 2009; Junaidi, 2013; Gnerre et al, 2015).

Prevalence of peripheral vertigo incidence rate, Benigna Paroxysmal Positioning Vertigo (BPPV) in the United States is about 64 out of 100,000 people with a tendency to occur in women (64\%). BPPV is estimated to occur frequently at the age of 51-57 years and is rare in under 35s without a history of head trauma. In 2008 in Indonesia the incidence of vertigo was about $50 \%$ of the elderly people aged 75 years. This is also the third most common complaint raised by sufferers coming to health care. In general vertigo is found $4-7 \%$ of the total population and only $15 \%$ are examined to a doctor (Dewanto, 2009). In 2013 the population of Malang city was about 835,082 people, and recorded in the year 2012-2013 as much as $19 \%$ of whom never felt vertigo (the health ministry of Malang, 2014)

Vertigo may affected the physical and psychological condition of the sufferer. Physical injury and muscle weakness can be experienced by vertigo sufferers, because in vertigo patients often lose balance caused by the disturbance of cranial nerve VIII (nucleus vestibular) which serves as a balance control, because the nerve also controls the head and movement of the eyeball. Due to the presence of the disorder the vertigo patient is not able to defend themselves to keep on standing condition with balanced and running regularly. Thus it could cause the risk of falling which resulted in physical injury to the patient. (Bayer, Warninghoff \& Straube, 2010). Patients with vertigo often experienced muscle weakness, this was often the case because people with vertigo do not perform activities. Patients with vertigo more often lie down or just activity on the bed, due to vertigo sufferers often felt tired and unable to stand up and beraktifitas. Because lying too long and limited movement could cause muscle weakness. (Wahyudi, 2012).

Treatment of vertigo was by: (1) pharmacology, as a causal therapy that aims to correct vestibular imbalances through the modulation of neural transmission with anticholinergic drugs; (2) nonpharmacology by doing exercises that may reduce the symptoms, such as the Brandt-Daroff method of exercise as a desensitization effort of semicircular receptors. It is expected that with this simple exercise can reduce the symptoms of vertigo that arise and can improve the quality of life of the patient (Wreksoatmodjo, 2004).

Erratic vertigo disorders, drugs that continue to be consumed, and environmental conditions cause stress so it can cause depression. Due to the conditions as described, it needed good coping so as not to cause excessive anxiety that can result in disruption of daily activities (Mundhenke, 2010). Vertigo can also be caused by psychological stressors. vertigo is an important problem to be studied in order to obtain the data in a complete qualitative related to the complaint and its impacted both to physical and psychological and social. Thus it can give a subjective picture of patients vertigo and family so that people can prepare themselves both physically and psychologically if experiencing the same complaints. The description can be obtained through a qualitative approach with emphasis on exploring the subjective experience of case studies.

\section{METHOD}

This research used qualitative research design with case study approach. This study involved seven participants of vertigo sufferers who live in Panti Janti Malang. Participants were selected by purposive sampling technique and using data saturation 
principle. With inclusion criteria: (1) diagnosed with vertigo proven by the testimony of himself or the people around him, or showing authentic evidence of examination results; (2) The patient was over 18 and willing to be a participant by signing a letter of willingness as partisans; (3) Suffer from Vertigo more than 1 year and can told the experience well. Data collected method with indepth interview using semi structured interview technique then analyzed data content analysis using cholaizzi method

\section{RESULTS AND DISCUSSION}

Participants in this study were vertigo patients who were in the area of Puskesmas Janti Malang totaling 7 people who can told their experience as vertigo sufferers with the characteristics as illustrated in table 1 and table 2, namely: (1) average age 44.9 years ( SD: 14,67), (2) average of vertigo for 6.9 years (SD: 3,33), (3) 86\% female, (4) 57\% high school educated, (5) $71.4 \%$ worked in the private sector, (6) $71 \%$ married status, and (7) $57 \%$ of participants said frequent relapse. As illustrated in table 1 and table 2.

Table 1: Characteristics of participants based on age and duration of vertigo at Janti Pubic Health Centre in Malang on 2015

\begin{tabular}{llll}
\hline Characteristics of participants & Means (years) & Max - Min (years) & SD \\
\hline Age & 44,9 & $59-22$ & 14,67 \\
\hline Duration of vertigo & 6,9 & $13-3$ & 3,3 \\
\hline
\end{tabular}

Table 2: Characteristics of participants by sex, level of education, and occupation in patients with vertigo at Puskesmas Janti Malang in 2015

\begin{tabular}{|c|c|c|}
\hline Characteristics of participants & Frequency (f) & Percentage (\%) \\
\hline \multicolumn{3}{|l|}{ Sex } \\
\hline - Men & 1 & 14 \\
\hline - Women & 6 & 86 \\
\hline \multicolumn{3}{|l|}{ level of education } \\
\hline - Senior high school & 4 & 57 \\
\hline - $\quad$ university (S-1) & 3 & 43 \\
\hline \multicolumn{3}{|l|}{ Occupation } \\
\hline $\begin{array}{ll}- & \text { government employees }\end{array}$ & 1 & 14,3 \\
\hline - private employment & 5 & 71,4 \\
\hline - $\quad$ Student & 1 & 14,3 \\
\hline \multicolumn{3}{|l|}{ Marital status } \\
\hline - $\quad$ Married & 5 & 71 \\
\hline - $\quad$ Not married & 2 & 29 \\
\hline \multicolumn{3}{|l|}{ Recurrence } \\
\hline - often & 4 & 57 \\
\hline - $\quad$ sometimes & 3 & 43 \\
\hline
\end{tabular}

From the results of in-depth interviews and combined with field notes which further conducted content analysis using steps from Colaizzi. The researchers identified eight themes that represented participants' experiences during vertigo:

a. Vertigo Arrived Suddenly

This theme was an early theme unearthed by researchers before going deeper into other theme themes. Patients with vertigo do not know he was stricken with vertigo, many of the patients who associate it with the symptoms of the disease in general. Because when vertigo appears patients complain of symptoms that were almost the same as symptoms of the disease in general. If its first felt of 
this symptoms will assume as a symptom of ordinary diseases. But the problems found at the time of research, the vertigo appears suddenly so that the patient did not know that he was attacked by vertigo. Category obtained by researchers is a symptom of vertigo is not known by the patient, symptoms of vertigo are considered symptoms of ordinary diseases, vertigo occurs suddenly. It is as follows:

"... Ou .. first time do not know if this is a complaint of vertigo, well it hurts vertigo the body feels weak can not do anything, (seen holding his body ...) it feels very dizzy and headache really, like what ya ... (furrow eyebrows ...) It feels haggard and body limp. Like wanting to bang against the wall. It was so sick that I was taken to a hospital ... "(P2).

"... I do not know, suddenly relapsed sick. That time when my complaints appeared at home ... after being taken to the doctor in the afternoon I just found out that I got vertigo. Yes at first I do not know... "(P6)

"... No mas, yes ordinary day-to-day, after waking up in the morning continue to work. which obviously suddenly dizzy and feels "nyut-nyut". Sometimes at work or rest at home suddenly vertigo ... "(P5)

From the results of interviews and observation research found that sudden changes in physical position in vertigo patients will greatly affect the complaints. This situation was in accordance with the results of research conducted by Yan Edward, Yelvita Roza, 2014 in the Diagnosis and Management of Positive Vertigo Benign Paroxysmal (BPPV) Based on the Head Roll Test states that BPPV was the most common in patients with vertigo, from the number of patients examined himself on medical personnel. Vertigo position arises when the head taked a position or a certain attitude

In a study conducted by Lumbantobing on Neurological Disorders in 2004, it was also explained that the symptoms of vertigo may appear suddenly due to the disturbance of rasti equilibrium that underwent sudden changes, rasti or organs that participate in regulating the balance of race ranging from vestibular rasti, visual racial and rectal somato rasti can be caused by a cause that has been suffered by the patient within a certain period of time as well as a disease that can affect the balance of the patient as can be found in the elderly who begin experiencing rastictive changes that can lead to clinical disorders such as vertigo

b. Physical and Psychological Stressor Cause Recurrence

Patients with vertigo generally excessive activity so forgot the needs of the body to rest, because physical and psychological are forced to work continuously so that it could cause symptoms of vertigo appear. So the researchers found that the category of vertigo relapse due to excessive busyness and vertigo relapse due to stress. Based on the category of vertigo relapse due to excessive bustle one of the causes of vertigo could appear triggered by excessive activity that cannot be accepted by vertigo sufferers. As stated by the following participants:

"... if I'm dizzy, i can't wake up, if I wake up immediately cause vomiting. so if I get exhausted immediately my vertigo relapse ... "(P3)

"... Usually when I'm stressed, I work in a hurry (eyebrows up) doing the job until very tired and if too long in front of the laptop (hands to hair). Yesterday in the fasting month I work hard to prepare for the holiday, 
hehehehe .... (smile) before the fasting month the cause is similar to that ... "(P1)

The condition of vertigo was very difficult to predict when it comes because when the vertigo relapse is often preceded by a cause, the cause also varies in each individual condition of vertigo which sometimes appear then suddenly healed and sometimes in a certain period of recurrence, causing a vertigo patient not want to condition the vertigo that experienced an obstacle to the activity so that the patient still undergoing activities as usual. Mundhenke, (2010) in a journal Vertigo: A Common Problem in Clinical Practice. At first vertigo is often complained of due to the conditions of life that are full of pressure both on the physical and physical tuntuan conditions can cause a sustained stress

c. Physical Discomforts the Impact of Vertigo

All patients when the vertigo relapse also felt like swirling, headache, weakness, dizziness, nausea. So the researchers found the following categories:

1. Like swirling. expressed as a sensation of vision and felt.

2. Headache. expressed by the participants as the most painful vertigo experience.

3. Weakness. experienced by some participants as disturbing conditions, thus inhibiting the mobility of participants.

4. Nausea. expressed by the participants in response to the condition

d. Vertigo sufferers at risk of physical injury

The condition experienced by vertigo sufferers was often uncertain and suddenly. Response to diseases that appear by each participant is also different although similar. A vertigo sufferer could hurt himself for not being able to withstand the perceived condition. Even some participants say until there was a loss of consciousness when the vertigo relapse Possible sufferers were injured expressed from the categories of phrases vertigo sufferers such as: the sufferer losed consciousness and self-control ability when the vertigo relapse.

Physical injury and muscle weakness can be experienced by patients with vertigo, due to vertigo patients often lose balance caused by disruption of nerve to VIII (nucleus vestibular) as a balance controller, controls the head and movement of the eyeball. so that vertigo patients were unable to maintain balance. So that can cause the risked of falling which resulted in physical injury in patients, most of the patients experience vertigo pain and interspersed with stress that burdens the brain. This condition could affect the physical weakness of the patient so that it could cause fainting or even a mild to severe brain hearing (Bayer, Warninghoff, \& Straube, 2010)

e. Striving to Reduce Vertigo

When the vertigo experienced by the recurrent participant then many ways done by participants to reduce the symptoms, the expectations of participants for the effort made to reduce or eliminate symptoms of vertigo that arised when it happened or will. These efforts were: (1) resting was an effort to prevent vertigo symptoms from getting worse, (2) taking medication as an attempt to relieved symptoms, and (3) calming down as an attempted to prevent vertigo symptoms from getting worse expressed by participants as the easiest effort which was done when symptoms of vertigo appear. 
Generally the patient knew the management when the vertigo relapses then the patient checks his condition to the relevant medical personnel, or from patients who first suffered vertigo, or searching from various literature. The purpose of vertigo treatment, other than causal (if found cause), was to correct vestibular imbalance through neural transmission modulation; generally used drugs that are anticholinergic. In addition to drug therapy patients with vertigo could also perform physical exercises that could reduce the symptoms (Wreksoatmodjo, 2004)

f. Require support from family's and nearby person.

Patients with vertigo generally ignored the condition. the uncertain condition of vertigo disorder and the demands of the patient's life that did not tolerate the condition experienced by the patient, causing the participants sometimes forced to live the same life as people in general. In this study revealed that the support of the people around was very helpful in maintaining the health condition of the patient.

The role of the family was very important where the erratic condition of a vertigo sufferer requires another person to prevent himself from injury. The nearest person who can be expected to look after them is the family itself, where their concern was very meaningful as described by (Potter \& Perry, 2005) in which the family was a primary family member support system, the family is seen as a system, so if within the family one person suffering from illness or having problems will affect other family members. Family involvement in client care would improve optimal outcomes compared to individual nurses only.

Uncertain condition of vertigo pain that at any time could relapse cause the patient experiencing stress. ill condition was a state where physical, emotional, intellectual, social, disturbed development. Not only the state of the disease process, therefore illness was not the same as the disease. So a vertigo sufferer needed to get support from family members or the people around him, it is important because of the uncertain vertigo condition, the attitude of patients who want to opened in telling the actual conditions experienced will help the patient itself in the face of health status experienced (Potter \& Perry, 2005).

\section{CONCLUSION}

Vertigo was a complaint not only related to physical disorders, but also related to psychological problems that affect the psycho-socio-spiritual dimension of the sufferer. The experience of vertigo patients during their life states that the unstable vertigo condition of the attack made the patient's condition becomes very unstable and greatly affect the daily life. So it needed attention and support from all parties, including the closest people, family and health workers.

\section{REFERENCES}

Bayer, O., Warninghoff, J.C., Straube, A. (2010). Diagnotic Indices For Vertiginous Diseases. Journal BMC Neurology 2010; 10 (98)

Dewanto, G., Suwono, W,J., Riyanto, B., Turana, Y. (2009). Panduan Praktis Diangnosis \& Tata Laksana Penyakit Saraf. Jakarta : EGC 
Edward, Y., Roza, Y. (2014). Diagnosis dan Tatalaksana Benign Paroxysmal Positional Vertigo (BPPV) Horizontal Berdasarkan Head Roll Test. Jurnal Kesehatan Andalas $3: 1$

Gnerre, P., Casati, C., Frualdo, M., Cavalleri, M, \& Guizzetti, S. (2015). Management of Vertigo: from Evidence to Clinical Practice. Italian Journal of Medicine 2015; 9:180-192 doi:10.4081/itjm.2015.437

Junaidi, I. (2013). Sakit Kepala, Migrain, dan Vertigo. Jakarta; Buana Ilmu Populer.

Lumbantobing, S.M. (2001). Vertigo. Jakarta : Fakultas Kedokteran Universitas Indonesia

Mundhenke, M. (2010). Vertigo: A Common Problem in Clinical Practice. Journal of Biomedical Therapy Volume 4 No 2

Potter, P.A., Perry, A.G., (2005). Buku Ajar Fundamental Keperawatan: Konsep, Proses, dan Praktik. Edisi 4, Volume 1, Alih Bahasa, Asih, Y.,dkk. Jakarta: EGC

Wahyudi, K.T. (2012). Vertigo. Jurnal Medical Department PT Kalbe Farma Tbk. Volume $39: 10$

Wreksoatmodjo, B. R. (2004). Vertigo: Aspek Neurologi. Cermin Dunia Kedokteran No. 144 